ZOOLOGIA 32 (6): 492-496, December 2015

http://dx.doi.org/10.1590/S1984-46702015000600009

\title{
Autonomic regulation of heart rate during specific dynamic action associated with digestion in the bullfrog Lithobates catesbeianus
}

\author{
Débora Claësson ${ }^{1,2, *}$, Augusto Shinya Abe' \& Tobias Wang ${ }^{1,2}$
}

\author{
${ }^{1}$ Departamento de Zoologia, Instituto de Biociências, Universidade Estadual Paulista. Avenida 24A, 1515, Bela Vista, \\ 13506-900 Rio Claro, SP, Brazil. \\ ${ }^{2}$ Zoophysiology, Department of Bioscience, Aarhus University. C. F.Møllers Allé 3, 8000 Aarhus C, Denmark. \\ *Corresponding author. E-mail: deboraclaesson@gmail.com
}

\begin{abstract}
Feeding causes a substantial rise in the aerobic metabolism of all vertebrates, which is met by a rise in heart rate to secure adequate oxygen delivery, as well as intestinal nutrient absorption and transport between organs. To study the autonomic regulation of this postprandial tachycardia in an amphibian, we placed arterial catheters in individuals of the bullfrog, Lithobates catesbeianus (Shaw, 1802), to measure their blood pressure and heart rate. Heart rate in experimental subjects increased from a fasting value of $42.5 \pm 2.5$ to $52.5 \pm 1.6$ and $57.5 \pm 2.1 \mathrm{~min}^{-1}$ at 24 and 33 hours, respectively, after meals that corresponded to $5 \%$ of their body weight. Using an infusion of atropine and propranolol, we demonstrated that part of the postprandial tachycardia can be ascribed to a progressive decrease in parasympathetic tone ( $26 \pm 5 \%$ in fasting frogs to $6 \pm 5 \%$ by 33 hours into digestion), whereas the sympathetic tone remained unaltered at approximately $20 \%$. In addition to the withdrawal of vagal tone, digestion was also associated with an increase in the heart rate upon double-blockade (i.e., the combination of atropine and propranolol) from a fasting value of $44.5 \pm 0.9$ to $50.8 \pm 1.9 \mathrm{~min}^{-1}$ at 33 hours. This indicates that the postprandial tachycardia in frogs, as previously demonstrated for snakes, is partially governed by excitation of non adrenergic, non cholinergic (NANC) factors.
\end{abstract}

KEY WORDS. Adrenergic; cholinergic; postprandial tachycardia.

In vertebrates, digestion is associated with a rise in aerobic metabolism, a phenomenon commonly referred to as the specific dynamic action (SDA) (ANDRADE et al. 2005, SECOR \& FAULKNER 2002, SECOR et al. 2007). The SDA response of amphibians, as of other vertebrate groups, depends on the size and composition of the ingested meal, and may involve substantial increases in oxygen uptake that can last for several days (Wang et al. 1995, Powell et al. 1999, Busk et al. 2000, Secor \& FaulKner 2002, Andersen \& Wang 2003, Secor et al. 2007). It is also well-established that, in several species of frogs and toads, the SDA response is attended by a rise in heart rate $\left(\mathrm{f}_{\mathrm{H}}\right)$ which presumably supports the increased perfusion of the gastrointestinal organs to provide oxygen for digestive functions, to partake in the absorption of nutrients (DumSDAY 1990, WANG et al. 1995, ANdERsen \& WANG 2003). Similar responses are common in other vertebrates (WANG et al. 2001a).

The tachycardia that occurs during the SDA response is mediated, at least in part, by autonomic nervous regulation, to which a withdrawal of parasympathetic ("vagal") tone contributes significantly. The increased sympathetic tone is less important for the postprandial tachycardia, which is consistent with the long duration of the metabolic increment. In addition, a number of recent studies, particularly on snakes that exhibit very pronounced postprandial tachycardia, have shown that much of the tachycardia is mediated by increased non-adrenergic-non-cholinergic (NANC) factor on the heart (WANG et al. 2001b, SKovgaArd et al. 2009, ENok et al. 2012). This NANC stimulation can be ascertained from a rise in $\mathrm{f}_{\mathrm{H}}$, after double autonomic blockade (i.e., the combination of $\beta$-adrenoreceptor blockade and blockade by a muscarinic antagonist), and is caused either by the neurotransmitters released from the autonomic nerves projecting into the cardiac pacemaker, or from a circulating hormone. The latter possibility is supported by the observation that pharmacological blockade of the autonomic ganglia does not attenuate the $\mathrm{f}_{\mathrm{H}}$ response in snakes that are digesting, and plasma infusion from snakes that are digesting causes $\mathrm{f}_{\mathrm{H}}$ to increase in fasting snakes (ENOK et al. 2012). The amphibian heart, like the heart of other vertebrates, is dually innervated by adrenergic and cholinergic nerves that run in a common vagosympathetic trunk (WANG et al. 1999), but the autonomic regulation of the heart during SDA remains to be clarified.

Here we investigated the regulation of the postprandial rise in the heart rate of an amphibian species, the bullfrog Lithobates catesbeianus (Shaw, 1802), by placing arterial catheters in individuals, to measure their systemic blood pressure 
and to provide a way to administrate antagonist injections. Autonomic tones on the heart were obtained by pharmacological blockade of the autonomic tonus with the $\beta$-adrenergic antagonist propranolol and the muscarinic antagonist atropine. The complete blockade of autonomic tonus on the heart during SDA was used to verify the contribution of NANC factors to postprandial tachycardia.

\section{MATERIAL AND METHODS}

Thirty-four bullfrogs of both sexes and average mass of $206 \pm 8$ g were purchased from Ranário São Vicente de Paula (Conchal in the state of São Paulo, Brazil) and kept in an outdoor enclosure at the Jacarezário (UNESP Rio Claro, São Paulo, Brazil) under natural photoperiod and temperature regime (January to March - summer). Prior to being fasted for ten days, the frogs were weighted and force-fed bovine liver corresponding to $10 \%$ of their body mass to ensure that all animals were at a similar digestive state before we started the measurements.

The bullfrogs were anesthetized by emersion in benzocaine $(1.5 \mathrm{~g} / \mathrm{L})$, until their corneal reflex disappeared. They were then wrapped in humid tissue and placed on a surgical table. A $1.5 \mathrm{~cm}$ incision between the triceps femoris and gracilis minor gained access to the femoral artery, where a polyethylene catheter (PE50), filled with heparinized physiological saline, could be inserted by occlusive cannulation. The skin was closed with silk suture (Kruuse) and the catheter was secured to the back of the frog. The procedure lasted less than 30 min and the animals were placed under running water until they regained spontaneous ventilation (ANDERSEN \& WANG 2002). They were then placed in a transparent box $(34 \times 23 \times 10 \mathrm{~cm})$ with clean water under natural photoperiod at $28^{\circ} \mathrm{C}$. On the following day, the arterial catheter was connected to a disposable pressure transducer (Model PX600; Baxter Edwards, Ervine, CA), calibrated daily against a static water column, and recorded with a Biopac MP100 data acquisition system (Biopac Systems, Inc., Goleta, CA, USA) at $200 \mathrm{~Hz}$. Heart rate $\left(\mathrm{f}_{\mathrm{H}}\right)$ was derived from the pulsating pressure signal, and mean arterial blood pressure (MAP) was calculated using AcqKnowledge 3.9.1 software (Biopac Systems, Inc., Goleta, CA, USA). To avoid disturbing the frogs during recordings, and to ensure that their heart rate and blood pressure were back to lower stable values, all measurements were taken $30 \mathrm{~min}$ after the catheter had been connected to the transducer.

In eight frogs, MAP and $\mathrm{f}_{\mathrm{H}}$ were recorded during fasting and then at 15, 24, 33, 48, 57 and 72 hours after they were fed bovine liver corresponding to $5 \%$ of their body mass. In another series of experiments, autonomic regulation of $\mathrm{f}_{\mathrm{H}}$ was revealed in fasting and digesting bullfrogs at 24 and 33 hours past feeding (fasting $n=9$, digesting 24 hours $n=9$ and digesting 33 hours $n=8$ ) by measuring $\mathrm{f}_{\mathrm{H}}$ upon administration of atropine $(7.0 \mathrm{mg} / \mathrm{kg})$ followed by a subsequent injection of propranolol $(8.8 \mathrm{mg} / \mathrm{kg})$ when $\mathrm{f}_{\mathrm{H}}$ had stabilized. At 24 and 33 hours, SDA had provoked a significant increase in $\mathrm{f}_{\mathrm{H}}$. Atropine and propranolol were injected so that a double blockade coincided with 24 and 33 hours of digestion at the respectively groups. These autonomic blockades were verified by the lack of heart rate responses to â-adrenoreceptors and muscarinic antagonists.

Cholinergic and adrenergic tones were calculated on basis of the R-R interval $\left(1 / \mathrm{f}_{\mathrm{H}}\right)$ using the following formulas (Altimiras et al. 1997):

$$
\begin{aligned}
& \text { Cholinergic tone } \%=\frac{\mathrm{RR}_{\text {atropine }}-\mathrm{RR}_{\text {control }}}{\mathrm{RR}_{\text {double block }}} * 100 \% \\
& \text { Adrenergic tone } \%=\frac{\mathrm{RR}_{\text {atropine }}-\mathrm{RR}_{\text {double block }}}{\mathrm{RR}_{\text {double block }}} * 100 \%
\end{aligned}
$$

where $R R_{\text {control }}$ is the RR interval of fasting frogs, $R R_{\text {atropine }}$ is the $R R$ interval after infusion of atropine, while $R_{\text {double block }}$ is the RR interval after subsequent injection of propranolol.

Significant differences between groups were detected by one-way analysis of variance (ANOVA) and one way repeated measures ANOVA for normal distributed data and by MannWhitney and Holm-Sidak tests for non-parametric data. Differences were considered significant when $p<0.05$. Data is presented as mean \pm SEM.

\section{RESULTS}

A heart rate peak was achieved at 33 hours into digestion and the prolonged and significant rise in $\mathrm{f}_{\mathrm{H}}$ during digestion is shown in Fig. 1 ( $p<0.001$ for all groups; one-way ANOVA). By contrast, digestion did not influence MAP (Fig. 2). During measurements, frogs remained resting and undisturbed, to guarantee that the change in $\mathrm{f}_{\mathrm{H}}$ can be attributed to SDA.

The effects of the autonomic antagonists on $\mathrm{f}_{\mathrm{H}}$ are shown in Fig. 3 and Table 1 for both fasting and digesting frogs. Again, there was a significant rise in $\mathrm{f}_{\mathrm{H}}$ during digestion, with no change in MAP. Consistent with the removal of the inhibitory parasympathetic tone, atropine caused significant tachycardia, whereas double blockade after injection of propranolol caused a subsequent decline in $\mathrm{f}_{\mathrm{H}}$ in accordance with the inhibition of the excitatory role of the sympathetic innervation. The calculated tones based on these changes in $\mathrm{f}_{\mathrm{H}}$ are shown in Figs. 4-5 and Table 2, with a significant decline in the cholinergic tone during digestion ( $p=0.027$ and 0.007 at 24 and 33 hours, respectively; Mann-Whitney test), whereas the adrenergic tone was unaffected by digestion (Fig. 5).

Of particular relevance to the goals of the present study, the $\mathrm{f}_{\mathrm{H}}$ of frogs following double autonomic blockade was significantly elevated during digestion $(p=0.001$ and 0.007 at 24 and 33 hours, respectively; Holm-Sidak test), indicating the presence of a NANC factor exerting a positive chronotropic effect on $\mathrm{f}_{\mathrm{H}}$ (Fig. 3). Thus, the double-blocked $\mathrm{f}_{\mathrm{H}}$ of fasting frogs was $44.5 \pm 0.9 \mathrm{~min}^{-1}$, and increased to $48.8 \pm 0.5$ and $50.8 \pm$ $1.9 \mathrm{~min}^{-1}$ at 24 and 33 hours, respectively. 
Table 1. Heart rate (bpm) and systemic blood pressure $\left(\mathrm{cm} \mathrm{H}_{2} \mathrm{O}\right)$ for control (fasting) and digesting animals, before and after manipulation with atropine and propranolol.

\begin{tabular}{|c|c|c|c|c|c|c|c|c|c|}
\hline & \multicolumn{3}{|c|}{ Fasting } & \multicolumn{3}{|c|}{ Digesting (24 hours) } & \multicolumn{3}{|c|}{ Digesting (33 hours) } \\
\hline & Control & Atropine & Propranolol & Control & Atropine & Propranolol & Control & Atropine & Propranolol \\
\hline $\mathrm{HR}$ & $42.5 \pm 2.5$ & $54.2 \pm 2.1$ & $\begin{array}{c}44.5 \pm 0.9 \\
\text { (intrinsic heart rate) }\end{array}$ & $52.5 \pm 1.6^{*}$ & $58.7 \pm 1.6$ & $\begin{array}{c}48.8 \pm 0.5^{* * *} \\
\text { (intrinsic heart rate) }\end{array}$ & $57.5 \pm 2.1^{*}$ & $60.8 \pm 2.2^{\star \star}$ & $\begin{array}{c}50.8 \pm 1.9^{* * *} \\
\text { (intrinsic heart rate) }\end{array}$ \\
\hline$P_{s y s}$ & $30.8 \pm 2.6$ & $28.6 \pm 3.7$ & $29.3 \pm 2.6$ & $31.7 \pm 2.2$ & $31.6 \pm 1.9$ & $31.6 \pm 1.3$ & $40.5 \pm 3.3$ & $32.9 \pm 3.1$ & $33.5 \pm 2.9$ \\
\hline
\end{tabular}

* Significantly differences from fasting values.
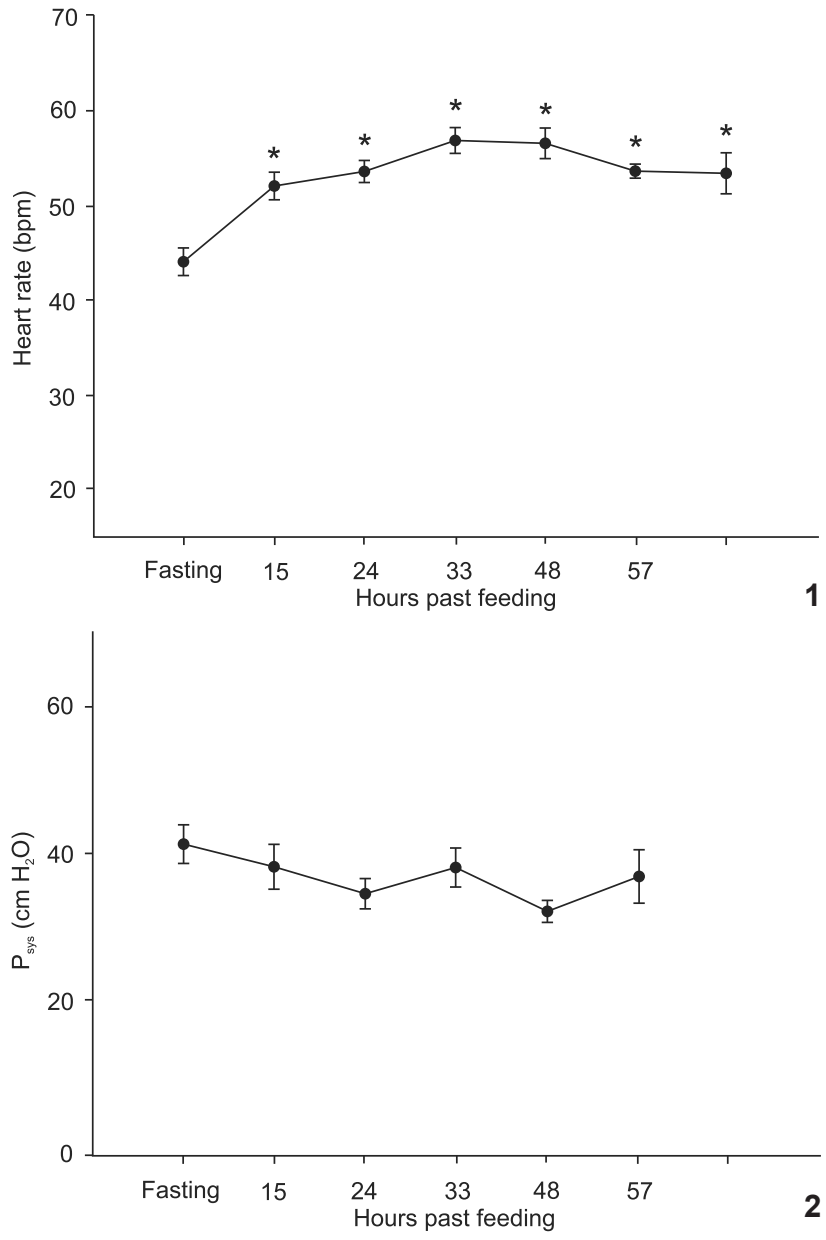

Figures 1-2. The effect of feeding in heart rate (1) and mean arterial blood pressure MAP (2) of Lithobates catesbeianus. Values are mean $\pm \mathrm{SEM}, \mathrm{N}=8$. Asterisks denote difference from fasting.

Table 2. Cholinergic and adrenergic tones on the heart during fasting and digestion. Asterisk shows significantly differences from fasting values.

\begin{tabular}{lccc}
\hline & Fasting & 24 hours & 33 hours \\
\hline Cholinergic tone (\%) & $25.9 \pm 4.6$ & $12.6 \pm 1.2^{\star}$ & $6.3 \pm 5.1^{\star}$ \\
Adrenergic tone (\%) & $22.2 \pm 5.1$ & $20.3 \pm 2.6$ & $20.0 \pm 3.1$ \\
\hline
\end{tabular}

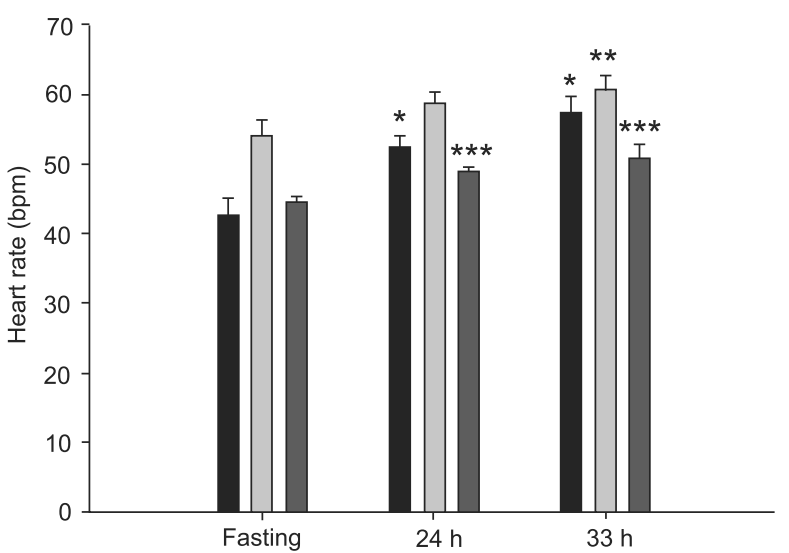

Figure 3. The effects of atropine and subsequent infusion of propranolol (double blockade) on heart rate in fasting and digesting (24 and 33 hours) bullfrogs. The double-blocked heart rate measured after propranolol increased significantly during digestion. Asterisk shows significantly differences from fasting values within same drug treatment. ( $\square$ ) Control, ( $\square$ ) atropine, ( $\square$ ) propranolol (double-blockade).

\section{DISCUSSION}

The bullfrogs in the present study exhibited a pronounced and sustained rise in $\mathrm{f}_{\mathrm{H}}$ during digestion. We did not measure the rise in oxygen consumption and thus the duration of SDA, but meals of similar magnitudes have been reported to double aerobic metabolism in anurans with maximal values occurring several days into the postprandial period (Wang et al. 1995, Busk et al. 2000, SeCor \& Faulkner 2002, SECor et al. 2007). Given that the rise in $f_{H}$ did not match the expected rise in metabolism, it is likely that stroke volume increased and that extraction of oxygen from the venous blood were elevated during digestion. As also reported for pythons, MAP did not change during the SDA response, which indicates a lower peripheral vascular resistance during digestion, as perfusion of the gastrointestinal organs is elevated by vasodilatation (SKovgaARD et al. 2009). Previous studies on toads revealed variable increases in $\mathrm{f}_{\mathrm{H}}$ during digestion (DumsDAY 1990, WANG et al. 1995, ANDERsen \& WANG 2003).

Our study shows that the postprandial tachycardia in bullfrogs is mediated by a release in vagal tone and a rise in 

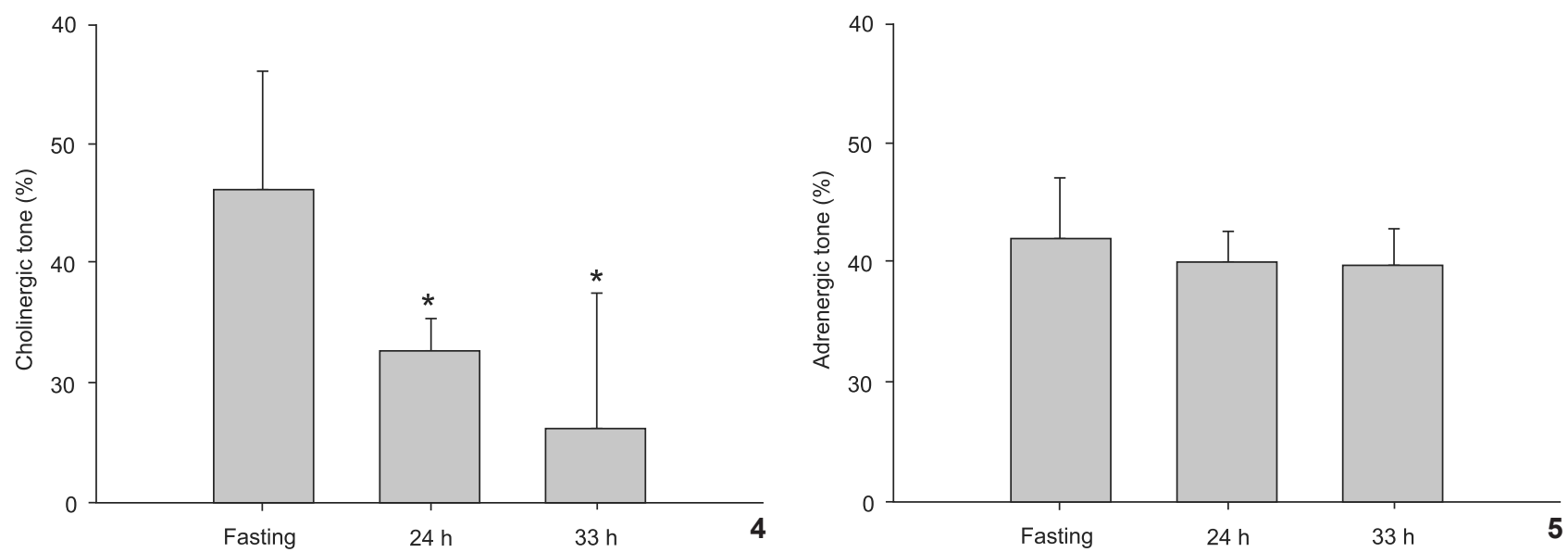

Figures 4-5. Cholinergic (4) and adrenergic (5) tones on the heart in fasting and digesting Lithobates catesbeianus. The significant reduction in cholinergic tone during digestion is marked by asterisks, whereas the adrenergic tone was unaffected by digestion. Values are presented as mean $\pm \mathrm{SEM}$; $(\mathrm{N}=8-9)$.

the double-blocked $\mathrm{f}_{\mathrm{H}}$. The adrenergic tone was relatively low in fasting frogs and did not contribute to the postprandial tachycardia. In a previous study using the snake Boa constrictor Linnaeus, 1758, a small reduction in the sympathetic tone during digestion was reported (WANG et al. 2001b), but the reduction in the cholinergic tone seems to be the primary mediator in the vertebrates studied so far (WANG et al. 2001b, SKovgaArd et al. 2009, Iversen et al. 2010). In this study, $\mathrm{f}_{\mathrm{H}}$ increased approximately 14 beats $\mathrm{min}^{-1}$ between fasting and digesting frogs (from $42.5 \pm$ to $57.5 \pm 2.1 \mathrm{~min}^{-1}$ at 33 hours) in the series of experiments where the autonomic tones were quantified (Figs. 4-5 and Table 2), and given that double blocked $\mathrm{f}_{\mathrm{H}}$ increased by about $6 \mathrm{~min}^{-1}$ (from $44.5 \pm 0.9$ to $50.8 \pm 1.9$ $\mathrm{min}^{-1}$ at 33 hours), the NANC contribution accounts for approximately half of the rise in $\mathrm{f}_{\mathrm{H}}$.

The NANC stimulation of the heart could stem from a release of excitatory neurotransmitters from the autonomic nerves innervating the cardiac pacemaker and/or represent a positive chronotropic effect exerted by circulating signal molecules, such as hormones released from the gastrointestinal organs in response to the presence of food. The latter seems to be the responsible factor in digesting snakes, since the ganglionic blocker hexamethonium does not reduce the NANC (ENOK et al. 2012). Furthermore, infusion of plasma drawn from digesting snakes exerts a clear positive chronotropic effect on $\mathrm{f}_{\mathrm{H}}$ in fasting snakes, even after double autonomic blockade (ENoK et al. 2012). Humans with cardiac transplant, hence devoid of cardiac innervation, also exhibit postprandial tachycardia, pointing to a humoral origin of the postprandial NANC response (WAALER et al. $2002,2006)$. If the NANC factor indeed does stem from circulating signal molecules such as regulatory peptides or hormones, released from gastrointestinal organs in concert with the stimulation of digestive processes, this response represents a type of cardiovascular regulation that occurs without the direct influence of the central nervous system. Nevertheless, although the postprandial NANC stimulation seems broadly distributed among vertebrates, there was no evidence for NANC stimulation in the European sea bass, Dicentrarchus labrax (Linnaeus, 1758), where the heart rate response to digestion was exclusively mediated by a reduction in the parasympathetic tone on the heart (IVERSEN et al. 2010).

Our present experiments using frogs could not identify the origin of the NANC stimulation of the heart during digestion in these animals. Answering this question may prove extraordinarily difficult because the autonomic neurons of amphibians contain a plethora of NANC factors that could be responsible. One obvious possibility is adenosine triphosphate (ATP), which is released from sympathetic nerves innervating the frogs' heart and exerts a positive chronotropic effect (MorRIS et al. 1981, Bramich et al. 1990). Thus, while we can conclude that the postprandial rise in heart rate in the bullfrog $L$. catesbeianus is mediated by the withdrawal of vagal tone and through the presence of a non-adrenergic, non-cholinergic factor, it is also evident that future studies are needed to elucidate the identity and relative contributions of the relevant hormones and neurotransmitters.

\section{ACKNOWLEDGMENTS}

This study was supported by The Danish Research Council. Travel support was provided by Aarhus University.

\section{LITTERATURE CITED}

Altimiras J, Aissaoui A, Tort L, Axelsson M (1997) Cholinergic and adrenergic tones in the control of heart rate in teleosts. 
How should they be calculated? Comparative Biochemistry and Physiology A. 118A: 131-139. doi: 10.1016/S03009629(96)00402-1

ANDERSEN JB, WANG T (2002) Effects of anaesthesia on blood gases, acid-base status and ions in the toad Bufo marinus. Comparative Biochemistry and Physiology 131: 639-646. doi: 10.1016/S1095-6433(01)00498-6

Andersen JB, WANG T (2003) Cardiorespiratory effects of forced activity and digestion in toads. Physiological and Biochemical Zoology 76: 459-470. doi: 10.1086/375439

Andrade DV, Cruz-Neto AP, Abe AS, Wang T (2005) Specific Dynamic Action in Ectothermic Vertebrates: A Review of Determinants of Postprandial Metabolic Response in Fishes, Amphibians and Reptiles, p. 305-324. In: STARCK JM, WANG $\mathrm{T}$ (Eds.) Physiological and Ecological Adaptations to Feeding in Vertebrates. Enfield, Science Publisher.

Bramich NJ, Edwards FR, Hirst GDS (1990) Sympathetic-nerve stimulation and applied transmitters on the sinus venosus of the toad. Journal of Physiology 429: 349-375.

Busk M, Jensen FB, Wang T (2000) Effects of feeding on metabolism, gas transport, and acid-base balance in the bullfrog Rana catesbeiana. American Journal of Physiology 278: R185-R195.

DumSDAY B (1990) Resting heart rate of the toad Bufo marinus - A long term study of individual differences and environmental influences. Physiological Zoology 63: 420-431.

Enok S, Simonsen LS, Pedersen SV, Wang T, Skovgaard N (2012) Humoral regulation of heart rate during digestion in pythons. (Python molurus and Python regius). AJP: Regulatory, Integrative and Comparative Physiology 302: R1176-R1183. doi: 10.1152/ajpregu.00661.2011

Iversen NK, Dupont-Prinet A, Findorf I, McKenzie DJ, WANG T (2010) Autonomic regulation of the heart during digestion and aerobic swimming in the European sea bass (Dicentrarchus labrax). Comparative Biochemistry and Physiology 156: 463-468. doi: 10.1016/j.cbpa.2010.03.026

Morris JL, Gibbins IL, Clevers J (1981) Resistance of adrenergic neurotransmission in the toad heart to adrenoreceptor blockade. Naunyn-Schmiedebergs Archives of Pharmacology 317: 331338. doi: 10.1007/BF00501315

Submitted: 10 May 2015

Received in revised form: 15 July 2015

Accepted: 29 August 2015

Editorial responsibility: Carolina Arruda Freire
Powell MK, Mansfield-Jones J, Gatten RE (1999) Specific dynamic effect in the horned frog Ceratophrys cranwelli. Copeia 1999: 710-717.

Secor SM, Faulkner AC (2002) Effects of meal size, meal type, body temperature, and body size on the specific dynamic action of the marine toad, Bufo marinus. Physiological and Biochemical Zoology 75: 557-571. doi: 10.1086/344493

Secor SM, Wooten JA, Cox CL (2007) Effects of meal size, meal type, and body temperature on the specific dynamic action of anurans. Journal of Comparative Physiology B 177: 165-182. doi: 10.1007/s00360-006-0119-2

Skovgaard N, Moller K, Gesser H, Wang T (2009) Histamine induces postprandial tachycardia through a direct effect on cardiac H2-receptors in pythons. American Journal of Physiology 296: R774-R785. doi: 10.1152/ajpregu.90466.2008

WaAler BA, Hisdal J, Eriksen M (2002) Circulatory responses to a meal in patients with a newly transplanted heart. Acta Physiologica Scandinavica 174: 101-108.

Waaler BA, Hisdal J, Ihlen H, Kjekshus J (2006) Mechanisms behind the postprandial increase in cardiac output: a clue obtained from transplanted hearts. European Journal of Applied Physiology 97: 516-520. doi: 10.1007/s00421-0060210-0

Wang T, Burggren W, Nobrega E (1995) Metabolic, ventilatory, and acid-base responses associated with specific dynamic action in the toad Bufo marinus. Physiological Zoology 68: 192-205.

Wang T, Hedrick MS, Ihmied YM, TaYlor EW (1999) Control and interaction of the cardiovascular and respiratory systems in anuran amphibians. Comparative Biochemistry and Physiology 124A: 393-406. doi: 10.1016/S1095-6433(99)00131-2

Wang T, Busk H, Overgaard J (2001a) The respiratory consequences of feeding in amphibians and reptiles. Comparative Biochemistry and Physiology a-Molecular and Integrative Physiology 128: 535-549. doi: 10.1016/ S1095-6433(00)00334-2

Wang T, Taylor EW, Andrade D, Abe AS (2001b) Autonomic control of heart rate during forced activity and digestion in the snake Boa constrictor. Journal of Experimental Biology 204: 3553-3560. 